\title{
Özel Bir Koleksiyona Ait Metal İşlemeli Örtülerde Oluşan Bozulmaların Tespiti Ve Belgelenmesi
}

Yrd. Doç. Dr. Hatice Tozun

\section{Özet}

Tarihi tekstiller, günümüzde tablolar veya heykeller kadar değerli olmaya başlamış olan karmaşık ve zengin nesnelerdir. Özünde diğer müze objelerine göre bozulmaya eğilimli organik malzemeler olması yüzünden, fiziksel ve kimyasal özelliklerini anlamak için bilimsel bilgi ve tekniklerden yararlanarak, bu nesneleri koruma bakış açısılya incelemek gerekmektedir. Bu çalışma ile özel bir koleksiyona ait bu nesneleri koruma bakış açısılya incelemek gerekmektedir. Bu çalışma ile özel bir koleksiyona ait
19.yüzyıldan kalma metal işlemeli iki adet örtü incelenerek, eserlerin belgelemeye dönük teknik analizi yapılmış ve mevcut durumu tespit edilmiştir. Teknik analiz sonucunda eserlerin hammaddesi, kullanılan renkleri, ölçüleri, dokuma tekniği ve onarım durumu ile ilgili verilere ulaşılmıștır. Metal ipliklerin durumu ve element analizi SEM-EDX (Enerji dağılımlı X-ray ile kullanılan taramalı elektron mikroskobu) ile tahribatsı ve mikro analiz yöntemlerinden HPLC-DAD sIvı kromotografisi ile de

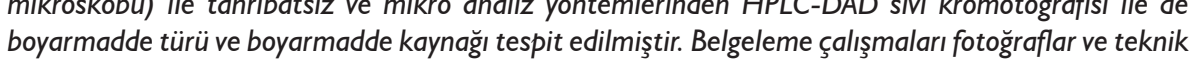
boyarmadde türü ve boyarmadde kaynağı tespit

Anahtar Sözcükler: Tekstil, i̇şleme, Metal İlik, Boyar Madde, Belgeleme

DETECTION AND DOCUMENTATION REGARDING DEGENERATION OF METAL ENGRAVED VEILS FROM A SPECIAL COLLECTION

\section{Abstract}

Nowadays, historical textiles became complicated and rich objects and started to gain just as much importance as paintings and sculptures. These objects should be handled and analyzed in a more preservationist way because of their organic ingredients that are far more likely to decompose than other museum objects. This work's purpose is to examine two veils with metal engravings from o special collection dated back to 19th century. According to this, technical analyses of pieces were made for documentation and their current state has been determined. With the technical analyses, made for documentation and their current state has been determined. With the technical analyses, metal engravings were determined using a SEM-EDX (a scanning electron microscope used with an energy dispersive $X$-ray); dyestuff and its origins were discovered using one of the nondestructive and micro analysis methods, HPLC-DAD liquid chromatography. Documentations include photographs and datas from technical analyses.

Keywords: Textile, Engraving, Metal Thread, Dyestuff, Documentation. 


\section{Giriş}

Tarihi tekstillerin analizi, ipuçlarını araştıran adli antropologlardan, arkeolojik veya etnografik bir tekstili tanımlamaya ve korumaya çalışan konservatörlere, müzecilere kadar pek çok araştırmacıya yardımcı olabilir. Tekstil, sanatsal ve tarihsel değeri göz önüne alındığında, arşiv belgelerini destekleyebilecek değerli tarihsel kanıt kaynakları olduğu düşünülen maddi çalışmaların sürekli artmasına katkıda bulunmaktadır. Tarihi tekstillerin aşamalı olarak incelenmesi; konservatörleri, tarihçileri, sanat tarihçilerini, kimyager ve daha birçok bilim insanlarını bir araya getirerek, disiplinler arası diyaloğu da sağlamaktadır.

Tarihi tekstillerdeki, müzelerdeki ve diğer kültürel miras kurumlarına ait olan materyallerin fiziksel-kimyasal özellikleri hakkında bilgi;

- Konservatörlerin, uygun materyalleri ve uygulamaları seçerek uygun koruma tedavileri hakkında karar verebilmeleri,

- Konservatörlerin, eserlerin özgünlüklerini doğrulamaları ve bunları müzelerde sergilemeleri ve uygun koruma koşullarını seçmeleri,

- Eserlerin güvenli ortamlarda düzgün bir şekilde depolanmasının sağlanması, böylece parçalanmalarının önlenmesi veya yavaşlatılması

- Belirli zamanlarda veya coğrafi alanda belirli tekniklerin uygulandığ gerçeğine dayanarak, tarihsel sorulara cevap verilebilmesi ve tekstillerin üretim yerinin ve tarihinin karakterize edilmesi için önemlidir.

Konservatörün amacl, tek bir nesneyi veya belgelenmesi gereken bir koleksiyonu incelemek, örneklemek, bilimsel araştırma ve uygulama ile ilgili kesin, eksiksiz ve kalıcı kayıtlar üretmek ve kalıcılığını sürdürmektir. Belgelerin türü ve kapsamı çeşitli faktörlere bağlı olabilir (Landi, 1992 : 50 - 51).

Tarihsel tekstillerin bilimsel araştırmalarında; ipliklerin, renklerin ve metal ipliklerin özelliklerini ve durumunu değerlendirmek için son yıllarda dünya genelindeki laboratuvarlarda önemli ilerlemeler kaydedilmiştir. Şu anda bu malzemeleri anlamada kullanılabilecek genis bir analitik teknik yelpazesi bulunmaktadır. Bunlardan bazıları; MO (optik mikroskopi), SEM-EDX (enerji dağılımlı X-ışını ile taramalı elektron mikroskopisi), FTIR (Fourier dönüşümü kızılötesi), UV / Vis dedektörüne bağlı HPLC, UHPLC'ye (ultra yüksek performanslı sıvı kromatografisi), Kütle spektrometresi, : XRF (X-ışını flüoresanı) veya XRD (X-ışını kırınımı), UV / Vis ve Raman dır.

Genel olarak, iplikleri ve durumlarını belirlemek için en yaygın kullanılan teknikler MO (optik mikroskopi) ve SEM-EDX (enerji dağılımlı X-ışını ile taramalı elektron mikroskopisi) dir. İplikleri boyar maddeler ile birleştiren mordanlar gibi iplikler üzerine ilave edilen kimyasal (inorganik) ürünlerin tanımlanmasına, metal ipliklerin kompozisyonunu ve durumunu değerlendirmeye izin vermektedir. MO ve SEM-EDX'in yanı sıra, FTIR (Fourier dönüşümü kızılötesi), daha önce inşa edilmiş çağdaş referans materyalleri verilerek bazı ipliklerin tanımlanmasına yardımcı olabilir. Boyarmaddeler için, UV / Vis dedektörüne bağlı HPLC ile daha fazla bilgi elde edilebilmektedir. Daha yakın zamanlarda, UHPLC'ye sahip yeni bir yöntem HPLC'den daha doğru sonuçlar verdiği için giderek daha da benimsenmektedir. Kütle spektrometresi teknikleri, boya maddelerinin kaynakları hakkında daha fazla bilgi sağlayarak HPLC / UHPLC'yi desteklemek için çok yararlıdır. $X R F$ veya $X R D$, ipliklerin ve metal ipliklerinin bozulma derecesi hakkında bilgi sağlayabilirken, UV / Vis ve Raman, boyaların tanımlanması hakkında bilgi vermektedir (Degano ve Ribechini, 2009: 363-410; Osman, Kamal ve Zidan, 2014 : 459 - 468; Pauk ve Barták, 2014 : 3393 - 3410).

Bütün bu teknikleri gerçekleştirmek için, küçük tekstil iplikleri ve / veya metal iplikleri (yaklaşık 3-5 mm uzunluğunda) örneklemek gereklidir. Bu işlemler tekstillerin değeri, durumu ve estetiği göz önünde bulundurularak yapılmalıdır.

Bu çalışma ile 19.yüzyıldan kalma $50 \mathrm{~cm}$. eninde $145 \mathrm{~cm}$. uzunluğunda, Türk işi tekniği ile işlenmiş, pamuk ipliklerle dokunmuş, metal işlemeli iki adet örtü incelenmiştir. Bu amaç doğrultusunda, eserlerin belgelemeye dönük teknik analizi yapılarak mevcut durumu Kültürel Miras Ve Doğal Boya Labaratuvarı'nda gerçekleştirilen analizlerle tespit edilmiştir. Teknik analiz sonucunda eserlerin hammaddesi, kullanılan renkleri, ölçüleri, dokuma tekniği ve onarım durumu ile ilgili verilere ulaşılmıştır. Belgeleme çalıșaları ise fotoğraflar ve teknik analiz sonucu hazırlanan veriler ile yapılmıştır. Metal ipliklerin durumu ve element analizi SEM-EDX ile tahribatsız ve mikro analiz yöntemlerinden HPLC-DAD sIVı kromotografisi ile de boyarmadde türü ve boyarmadde kaynağı tespit edilmiştir.

\section{Bulgular}

Araştırma kapsamında Saime Sirel koleksiyonuna ait 2 adet atkısı ve çözgüsü pamuk, bezayağı (B1/1) tekniği ile dokunmuş örtünün belgelenmesi amacıyla teknik bilgilere yer verilmiştir. 


\section{Numaralı Eser}
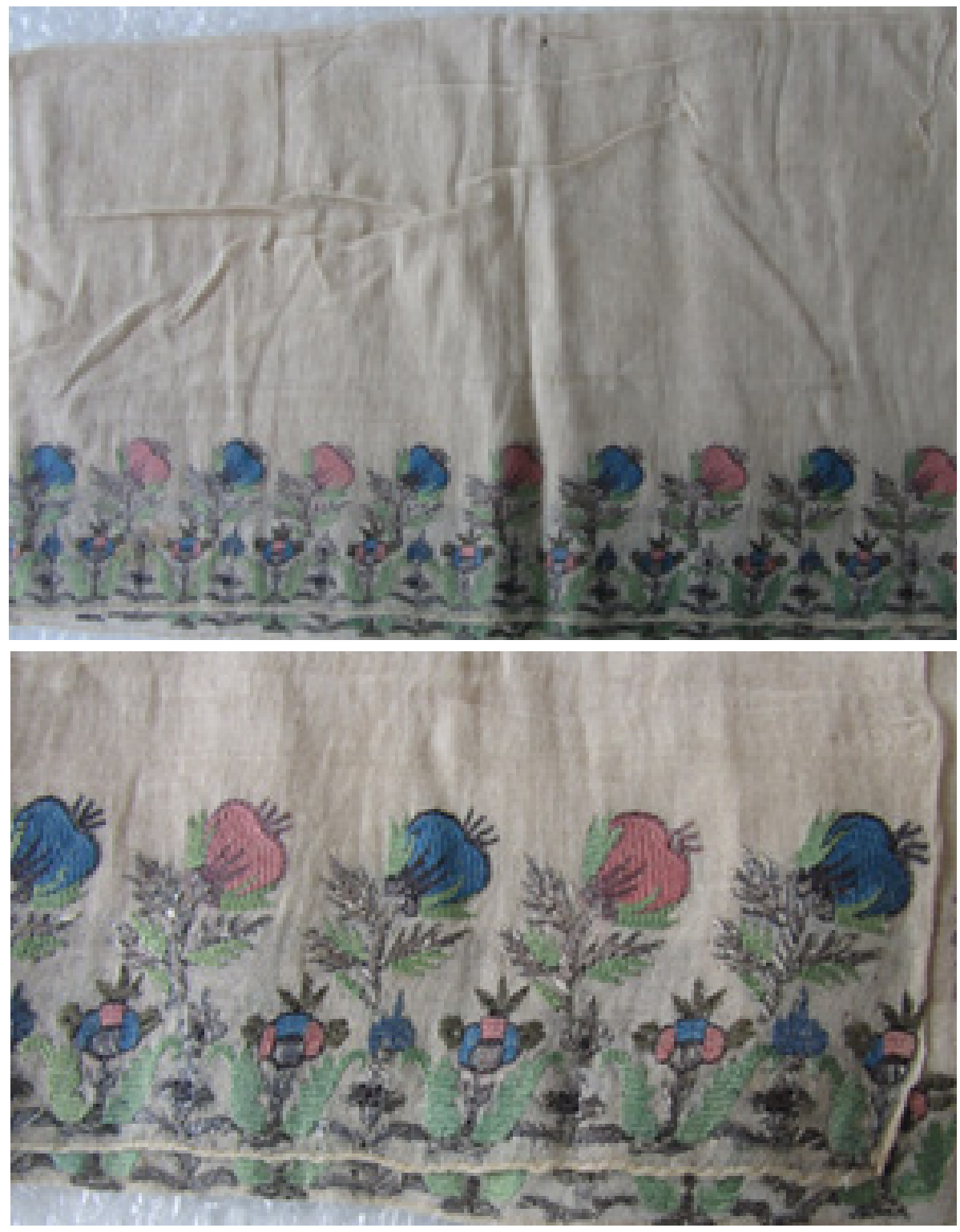

Görsel I. I Numaralı Eserin Görüntüsü

1 numaralı eser (Görsel 1) $50 \mathrm{~cm}$. eninde $145 \mathrm{~cm}$. uzunluğunda bir örtüdür. Örtünün atkı ve çözgü iplerinin hammaddesi pamuk olup, bezayağı (B1/1) tekniği ile dokunmuştur.
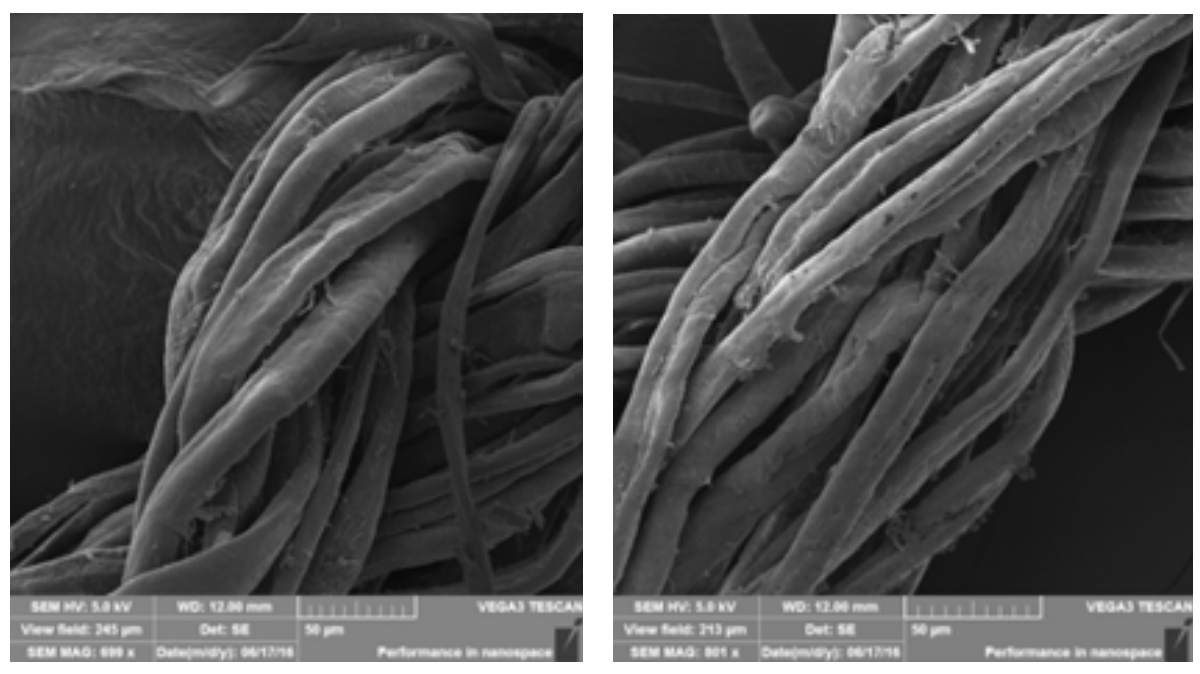

Şekil I. I Numaralı Eserin Lif Örneğinin SEM Görüntüleri
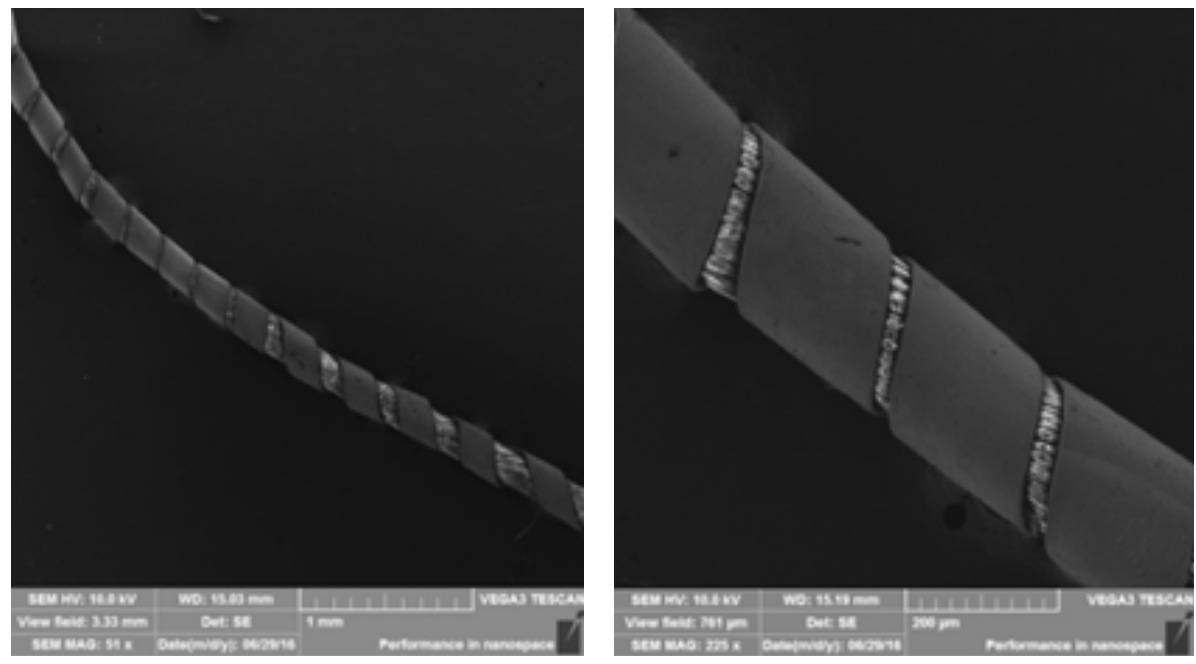

Şekil 2. I Numaralı Eserin Klapdan Örneğinin SEM Görüntüleri

HPLC (Şekil 1-2) ile boyarmadde analizi sonucuna göre boya spektrumu tespit edilmiştir. Gülkurusu renk ile pembe rengin analizinde aynı boyarmaddeler kullanılmıştır. Analiz sonuçlarına göre, bu renkleri elde etmek için Brezilya ağacının gövdesi (Caesalpinia brasiliensis L.) ile boyama yapıldığı tespit edilmiştir. Bu bitki ticaret yoluyla Avrupa'ya ihraç edilmis olup Anadolu'da tekstil, Görsel boyamaları ve el yazmalarında sıkça kullanılmaktadır. Yeşil renkli örnekte datiscetin, emodin ve indigotin 
boyarmaddeleri saptanmıştır. Bu renk için iki bitki ile boyama yapılmıştır. Gence (Datisca cannabina L.) bitkisi ile Hindistan çividi (Indigofera tinctoria L.) ya da çivit otu (Isatis tinctoria L.) bitkilerinden birisi kullanılmıştır.

\begin{tabular}{|c|c|c|c|c|c|c|}
\hline \multirow{2}{*}{$\begin{array}{c}\text { Voltaj } \\
\text { Değeri } \\
(\mathbf{k V})\end{array}$} & $\begin{array}{c}\text { Oksijen } \\
(\mathbf{K})\end{array}$ & Sülfür (K) & Klor (K) & Bakır (L) & $\begin{array}{c}\text { Gümüş } \\
(\mathbf{L})\end{array}$ & Altm (M) \\
\cline { 2 - 7 } & 1.48 & 10.12 & 1.49 & 0.11 & 86.46 & 0.35 \\
\hline 10 & 1.84 & 6.27 & 0.81 & 0.52 & 90.55 & - \\
\hline 20 & 2.22 & 4.53 & 0.17 & 0.39 & 92.69 & - \\
\hline 30 & & & & &
\end{tabular}

Tablo I. I Numaralı Eserin Klapdan Örneğinde Tespit Edilen Element Yüzdeleri

HPLC (Şekil 1-2) ile boyarmadde analizi sonucuna göre boya spektrumu tespit edilmiştir. Gülkurusu renk ile pembe rengin analizinde aynı boyarmaddeler kullanılmıştır. Analiz sonuçlarına göre, bu renkleri elde etmek için Brezilya ağacının gövdesi (Caesalpinia brasiliensis L.) ile boyama yapıldığı tespit edilmiştir. Bu bitki ticaret yoluyla Avrupa'ya ihraç edilmiş olup Anadolu'da tekstil, Görsel boyamaları ve el yazmalarında sıkça kullanılmaktadır. Yeşil renkli örnekte datiscetin, emodin ve indigotin boyarmaddeleri saptanmıştır. Bu renk için iki bitki ile boyama yapılmıştır. Gence (Datisca cannabina L.) bitkisi ile Hindistan çividi (Indigofera tinctoria L.) ya da çivit otu (Isatis tinctoria L.) bitkilerinden birisi kullanılmıştır.
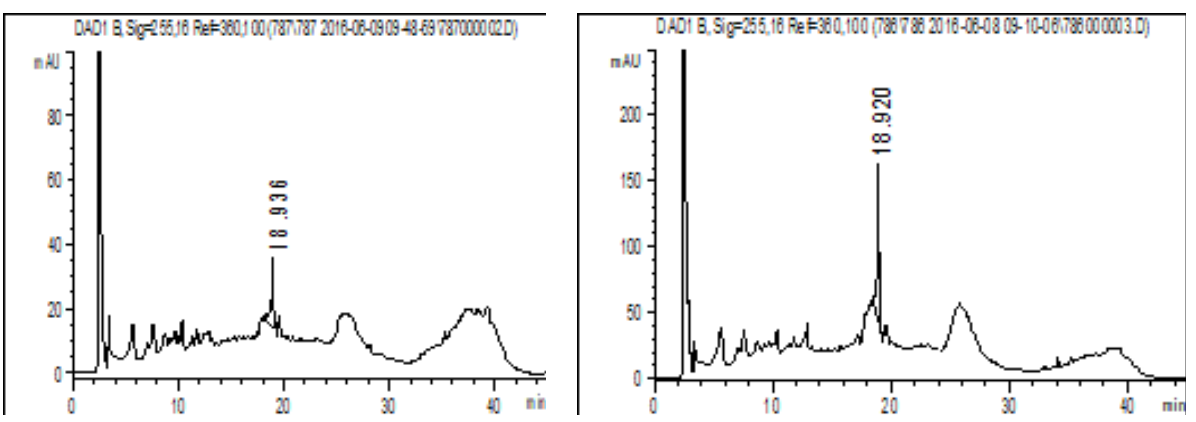

Şekil 3. I No.lu Eserin Gülkurusu Renkli Örneğin Kromatogramı (Solda)

Pembe Renkli Örneğin Kromatogramı (Sağda)
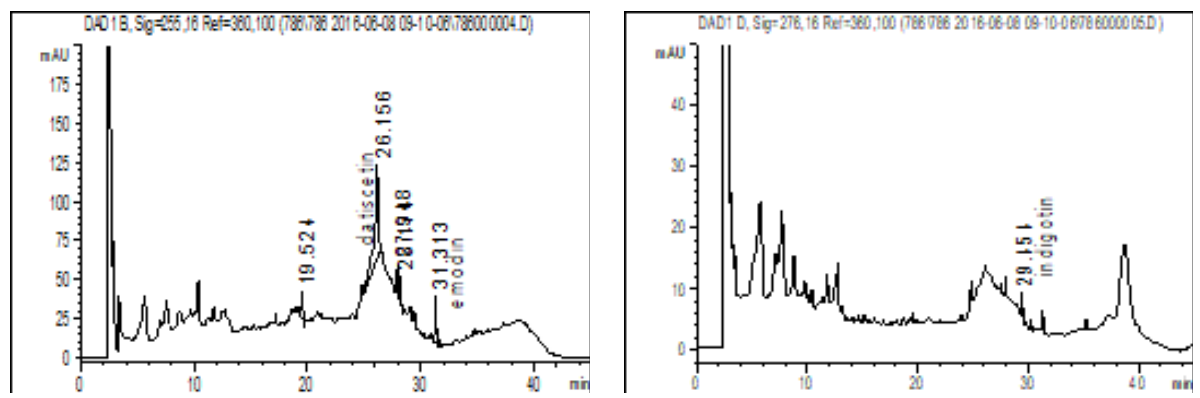

Şekil 4. I No.lu Eserin Yeşil Renkli Örneğin Kromatogramı (Solda)

Renkli Örneğin DMF Ile Çekilmiş Kromatogramı (Sağda)

\section{Numaralı Eser}

2 numaralı eser (Görsel 2) $50 \mathrm{~cm}$. eninde $145 \mathrm{~cm}$. uzunluğunda bir örtüdür. Örtünün atkı ve çözgü iplerinin hammaddesi pamuk olup (Şekil 5), bezayağ 1 (B1/1) tekniği ile dokunmuştur.

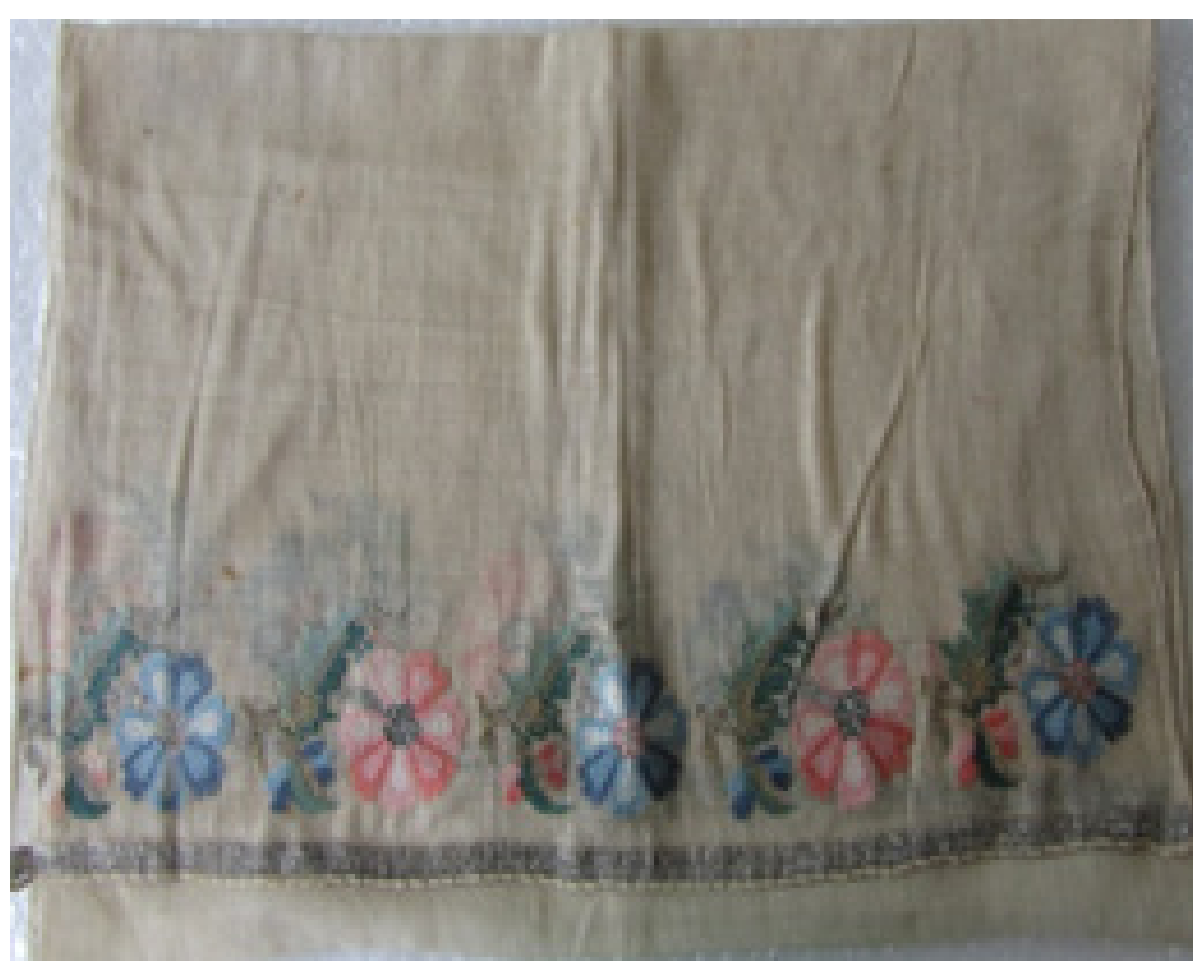

Görsel 2. 2 Numaralı Eserin Görüntüsü 


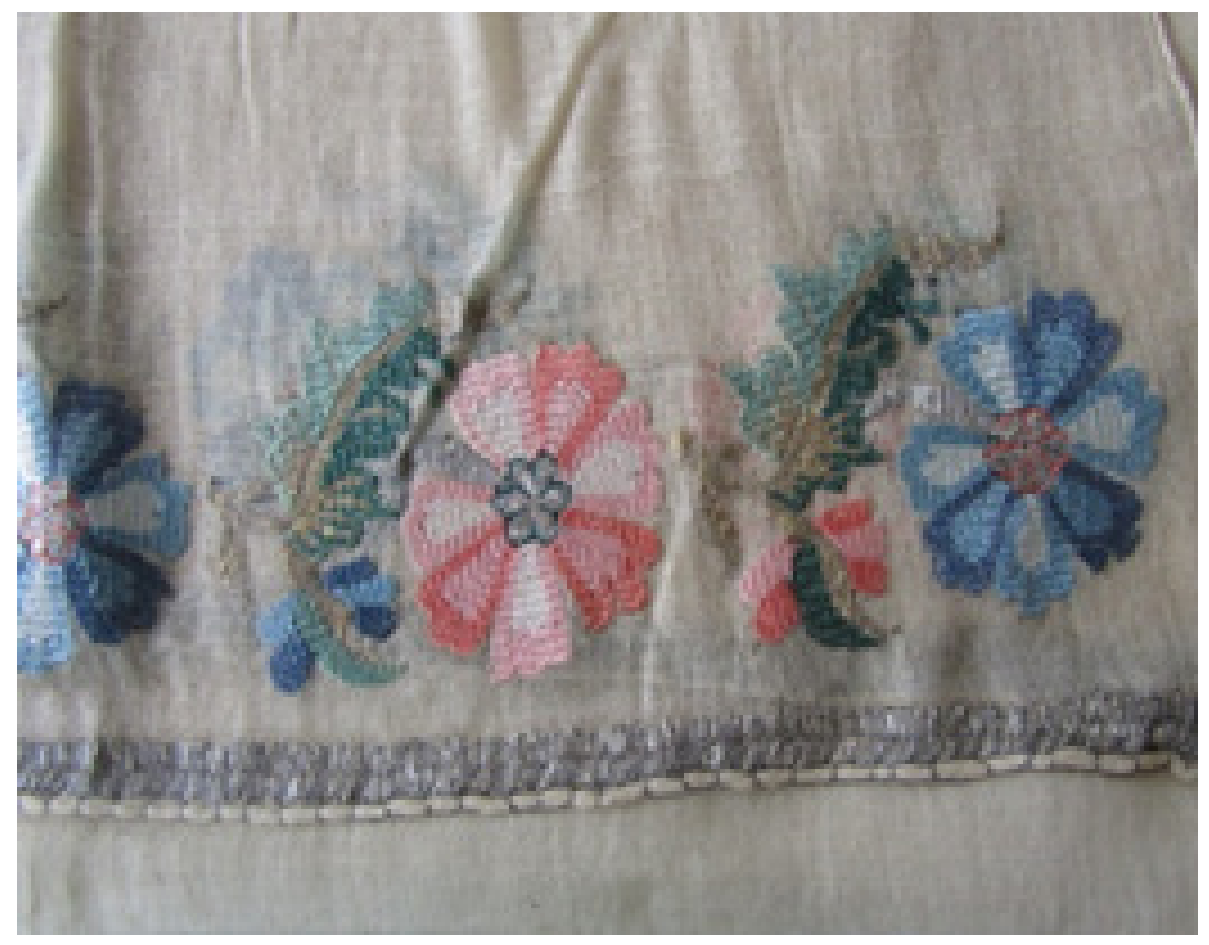

Görsel 2. 2 Numaralı Eserin Görüntüsü
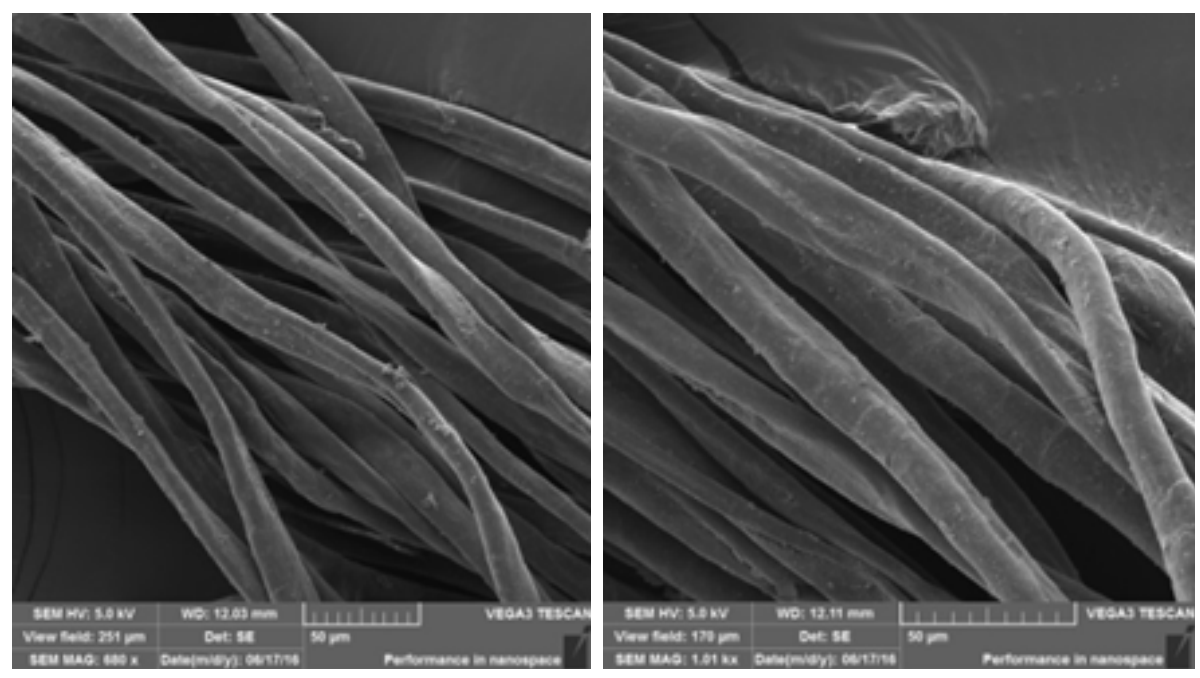

Şekil 5. 2 Numaralı Eserin Lif Örneğinin SEM Görüntüleri
Sarı klapdan ve beyaz klapdan örneklerinin hem SEM görüntüleri alınmış hem de EDX analizi yapılmıştır (Tablo 3). EDX analizi için üç farklı voltaj değeri ile çalışılmıştır. Böylece klapdanın alaşım mı yoksa kaplama mı olduğu anlaşılmıştır. $10 \mathrm{kV}, 20 \mathrm{kV}$ ve $30 \mathrm{kV}$ enerji düzeylerinde çalışılmıştır. Sarı klapdan örneğinde yüksek yüzdede gümüş (Ag) elementi saptanmış olup üst yüzeyi altın elementi ile kaplanmıştır. Beyaz klapdan örneğinde aynı şekilde yüksek oranda gümüş elementi ve çok az miktarda altın elementi tespit edilmiştir. Fakat bu örnekte kullanılan gümüş oranı beyaz klapdan örnekten hem çok daha fazla hem de kullanılan altın elementinin oranı çok daha azdır.
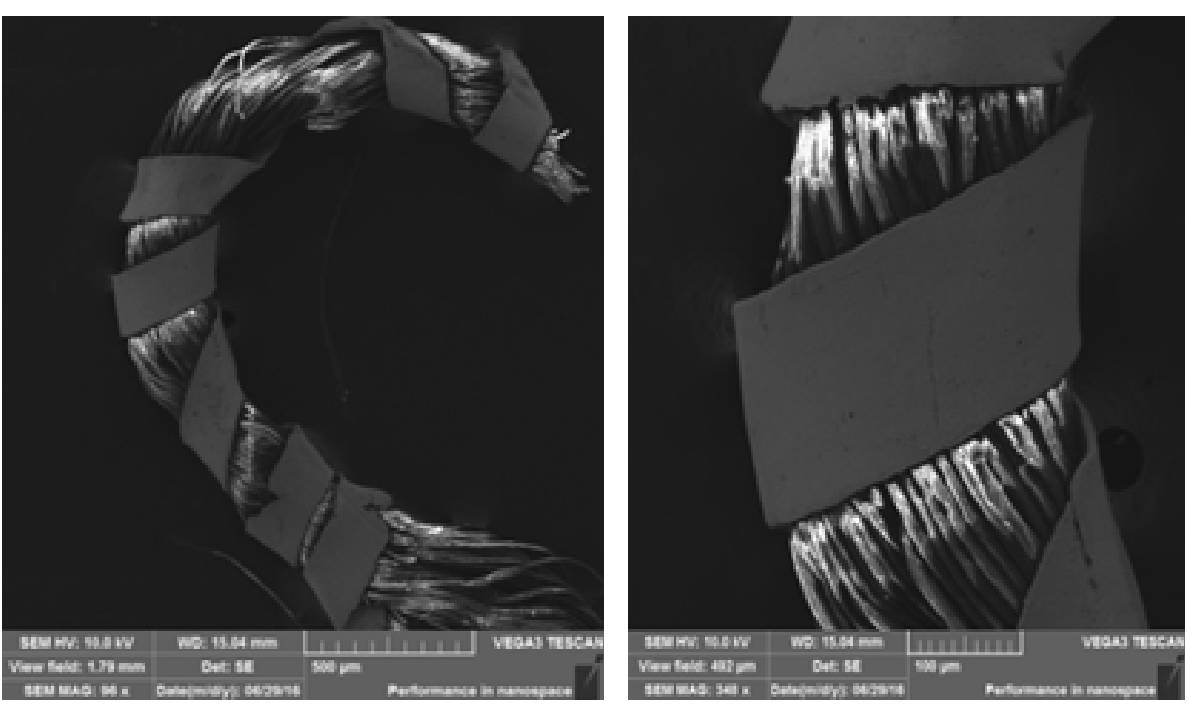

Şekil 6. Sarı Klapdan Örneğinin SEM Görüntüleri

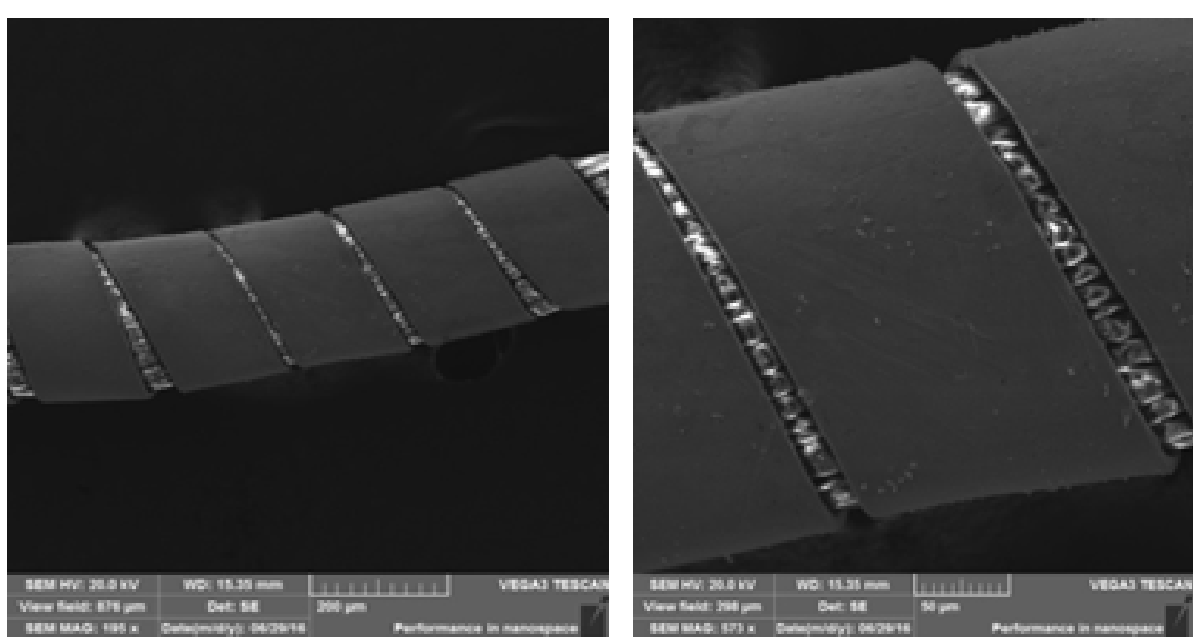

Şekil 7. Beyaz Klapdan Örneğinin SEM Görüntüleri 


\begin{tabular}{|c|c|c|c|c|c|c|c|}
\hline \multirow{2}{*}{$\begin{array}{l}\text { İndis } \\
\text { No. }\end{array}$} & \multirow{2}{*}{$\begin{array}{c}\text { Voltaj } \\
\text { Değeri } \\
(\mathbf{k V})\end{array}$} & \multicolumn{6}{|c|}{ Tespit Edilen Elementler (\%) } \\
\hline & & $\begin{array}{c}\text { Oksijen } \\
\text { (K) }\end{array}$ & $\begin{array}{c}\text { Sülfür } \\
\text { (K) }\end{array}$ & Klor (K) & $\begin{array}{c}\text { Bakır } \\
\text { (L) }\end{array}$ & $\begin{array}{c}\text { Gümüşs } \\
\text { (L) }\end{array}$ & $\begin{array}{c}\text { Altm } \\
\text { (M) }\end{array}$ \\
\hline \multirow{3}{*}{$\begin{array}{c}\text { Sarı } \\
\text { klapdan }\end{array}$} & 10 & 0.89 & 11.68 & 0.05 & 0.20 & 85.96 & 1.21 \\
\hline & 20 & 1.07 & 7.84 & - & 0.27 & 85.34 & 5.48 \\
\hline & 30 & 1.80 & 5.67 & - & 0.32 & 87.57 & 4.64 \\
\hline \multirow{3}{*}{$\begin{array}{c}\text { Beyaz } \\
\text { klapdan }\end{array}$} & 10 & 1.48 & 10.98 & 0.77 & 0.37 & 85.89 & 0.51 \\
\hline & 20 & 1.97 & 7.10 & 0.56 & 0.39 & 89.98 & - \\
\hline & 30 & 1.87 & 5.06 & 0.21 & 0.43 & 91.98 & 0.44 \\
\hline
\end{tabular}

Tablo 2. Sarı Ve Beyaz Klapdan Örneklerinde Tespit Edilen Element Yüzdeleri

Klapdan ipi sarı renkli örneğin boyarmadde analiz sonuçlarına göre, numunenin iki farklı bitki kaynağı ile boyandığı belirlenmiştir. Analiz sonuçlarına göre, boyacı sumağı (Rhus cotinus) ile cehri (Rhamnus sp.) bitkileri ile boyandığı saptanmıştır.

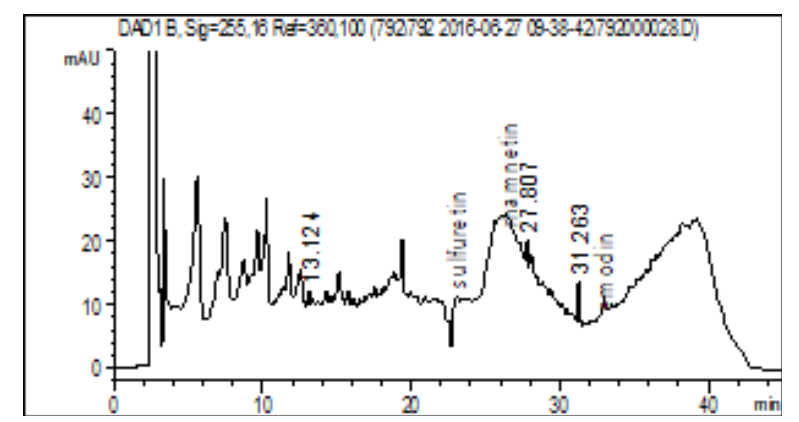

Şekil 8. Klapdan İpi Sarı Renkli Örneğin Kromatogramı

Koyu yeşil ve yeşil örneklerin boyarmadde analiz sonuçlarına göre (Şekil 1), aynı boyarmaddeler kullanılmıştır. Bu örneklerin Gence (Datisca cannabina L.) bitkisi ile Hindistan çividi (Indigofera tinctoria L.) ya da çivit otu (Isatis tinctoria L.) bitkilerinden birisi kullanılmışır.

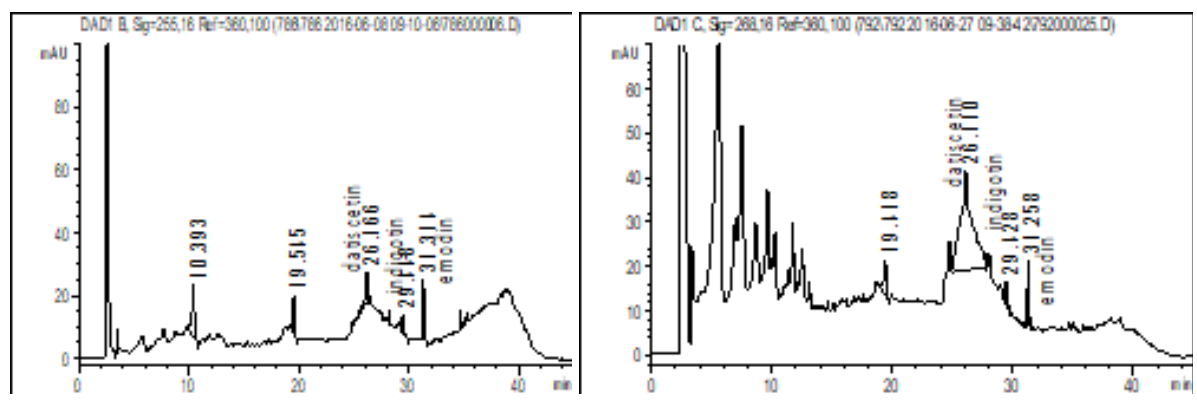

Şekil 9. Koyu Yeşil Örneğin Kromatogramı (solda)

Yeşil Renkli Örneğin Kromatogramı (sağda)

Açık mavi ve koyu mavi renkli örneklerin boyarmadde analiz sonuçlarına göre (Şekil 12), aynı boyarmaddeler tespit edilmiş olup bu örneklerin boyanması için Hindistan çividi (Indigofera tinctoria L.) veya çivit otu (Isatis tinctoria L.) bitkilerinden birisi kullanılmıştır.
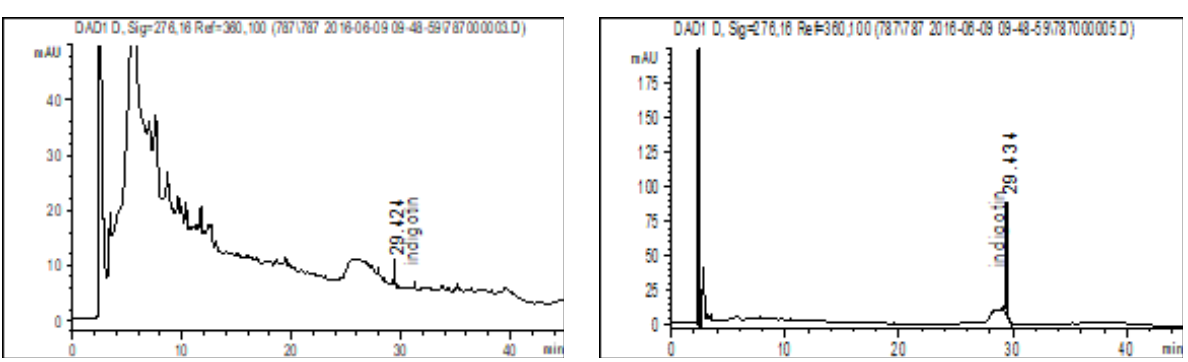

Şekil 9. Açık Mavi Örneğin Kromatogramı (solda)

Koyu Mavi Renkli Örneğin Kromatogramı (sağda)

Kırmızı renkli örneğin boyarmadde analiz sonucuna göre (Şekil 13), iki adet aynı grup boyarmadde tespit edilmiştir. Bu örneğin analiz sonuçlarına göre, bitkisel bir boya kaynağı ile boyandığı kuvvetle muhtemeldir. Fakat hang bitki ile boyandığı tespit edilememiştir. Pembe renkli örneğin ise, bitkisel bir boya kaynağı ile boyandığı kuvvetle muhtemeldir. Fakat hangi bitki ile boyandığı tespit edilememiştir. 

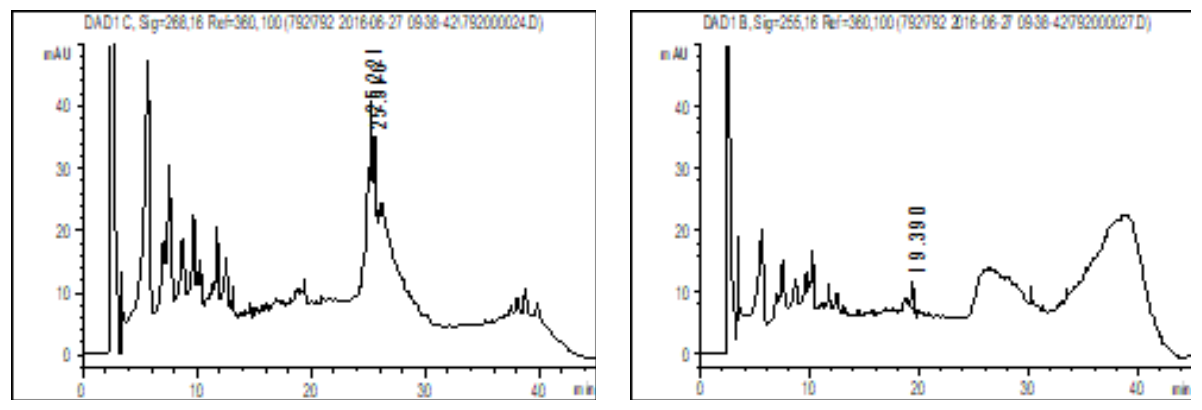

Şekil 9. Kırmızı Örneğin Kromatogramı (solda)

Pembe Renkli Örneğin Kromatogramı (sağda)

\section{Sonuç}

Konservasyon işlemini doğru yapabilmek için, inceleme, örnekleme, bilimsel araştırma ve uygulama ile ilgili kesin, eksiksiz ve kalıcı kayıtlar üretmek ve sürdürmekle mümkün olabilir.

Metal malzeme olarak klapdan kullanılmışır. Metal iplik kullanımdan dolayı eserlerde bozulma görülmektedir. Metal ipliklerde bakır ve gümüş oranı yüksek olduğu için kararma meydana gelmiştir. SEM-EDX ile yapılan analiz sonucunda iki örtüde de bakır ve gümüş kullanıldığı görülmektedir. Gülkurusu renk ile pembe rengin analizinde Brezilya ağacının gövdesi (Caesalpinia brasiliensis L.) ile boyama yapıldığı tespit edilmiştir. Yeşil renk örnekte renk için iki bitki ile boyama yapılmıştır. Gence (Datisca cannabina L.) bitkisi ile Hindistan çividi (Indigofera tinctoria L.) veya çivit otu (Isatis tinctoria L.) bitkilerinden birisi kullanılmıştır. Kırmızı ve Pembe renkli örneğin boyarmadde analiz sonucuna göre bitkisel bir boya kaynağı ile boyandığı belirlenmiş, fakat hangi bitki ile boyandığı tespit edilememiştir. Boyarmadde kökeninin bilinmesi restorasyon uygulamalıı açısından önemlidir. Organik ve inorganik boyar maddeler farklı restorasyon yaklaşımlarını yönlendirici uygulamalr içermektedir. Yapılan gözlem ve analiz sonuçlarına göre, örtülerde önceden konservasyon veya restorasyon işlemleri yapılmadığı tespit edilmiştir. Genel olarak iyi durumda olan örtüler, uygun saklanma koşullarında muhafaza edilerek konservasyon işlemi tamamlanabilir. 


\section{Kaynakça}

Barışta, Ö. H. (1999). Osmanlı Imparatorluğu Dönemi Türk Iş̧lemeleri. Ankara: Kültür Bakanlı̆̆ı Yayınları.

Degano, I., Ribechini, E., Modugno, F. \& Colombini, M.P. (2009). "Analytical Methods for The Characterization of Organic Dyes in Artworks and in Historical Textiles", Applied Spectroscopy Reviews , 44, 363-410.

Karadă̆, R. (2007). Doğal Boyamacılık. Ankara: Geleneksel El Sanatları ve Mağazalar İşletme Müdürlüğ̈̈ Yayınları.

Landi, S. (1992). The Textile Conservator's Manual, Examination, Options and Choice \& Recording, Handling and Preparation, Second Edition, Oxford, England: Butterworths.

Osman, E., Zidan, Y. ve Kamal, N. (20/4). "Using the Microscopic and Spectroscopic Techniques to Identify and Characterize Archaeological Artifacts", International Journal of Conservation Science, 5(4), 459-468.

Pauk, V., Barták, P. \& Lemr, K. (20 I4). “Characterization of Natural Organic Colorants in Historical and Art Objects by High-performance Liquid Chromatography", Journal of Separation Science, 37 (23), 3393-34I0. 